\title{
Crisis financiera internacional: UNA HISTORIA INCONCLUSA
}

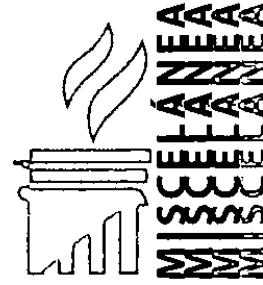

\section{Enrique Diaz Ortega}

Economista por la Pontificia Universidad Católica del Perú. Master en Economía (Cornell University, Ithaca, New York) Candidato PH.D. en Economía (Cornell University, Itacha, New York) Profesor del Área de Finanzas, Contabilidad y Economía en la Escuela de Administración de Negocios para Graduados - ESAN.

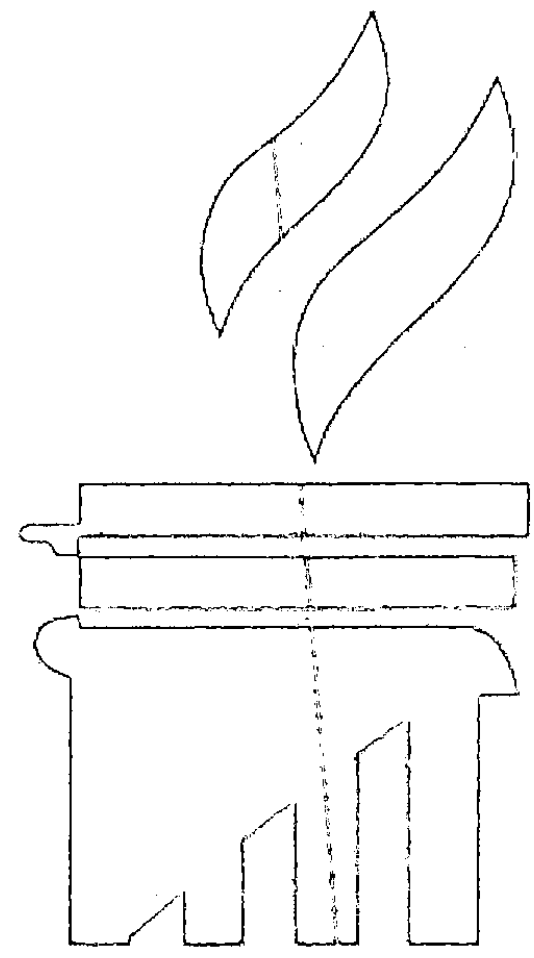

SUMARI0:

I. El escenario actual y sus causas aparentes.

II. Los eventos y la búsqueda de la solución.

III. Perspectivas del Panorama Internacional.

IV. Los efectos de la economía peruana.

V. El camino por delante. 
El viernes 10 de octubre del 2008, quedará registrado como un viernes fatídico pues todas las bolsas del mundo mostraron pérdidas significativas reflejando un nerviosismo y pánico casi generalizado acerca del futuro de los sistemas financieros de las principales plazas del mundo; particularmente la de EEUU. Tal eventualidad pondría al borde del colapso al sistema financiero internacional debido a la predominancia del mercado financiero y de capitales que mantiene dicho país. Una inmediata reacción de EEUU y las principales naciones europeas impidió que ello ocurriera, al menos por ahora.

En efecto, desde ese entonces hasta dos paquetes de rescate financiero han sido aprobados por el congreso americano comprometiendo recursos hasta por 1.5 trillones de dólares. Las preocupaciones, sin embargo, persisten, especialmente porque la economía del sector real ya acusa el impacto con una tasa de desempleo en EE.UU. en enero del 2009 que llegó a $7.6 \%$, la más alta desde el año 1992. Peor aún, la Organización Internacional del Trabajo (OIT) estima que hacia fines del 2009 los empleos perdidos por la crisis en el mundo ascenderían a 50 millones. Por todo ello los mercados financieros todavia titubean y no terminan de dar su aprobación a las políticas adoptadas.

La primera gran crisis del presente milenio viene todavía escribiéndose y sus efectos están en proceso de evaluación; sin embargo ya hemos constatado que se trata de la mayor crisis en muchas décadas; comparable posiblemente por su impacto con aquella de la Gran Depresión de 1929. De esa opinión es por ejemplo el propio George Soros.?

Sí bien hay un consenso que la crisis se gesta en EE.UU., se ha expandido a los demás mercados financieros de los países avanzados, y paulatinamente en los mercados emergentes también, conformando un desequilibrio casi mundial. En este contexto es importante entender lo mejor posible las causas de esta crisis, sus factores expansivos, los posibles escenarios que enfrentaremos (duración y profundidad), así como sus implicancias para el Perú.

\section{EL ESCENARIO ACTUAL Y SUS CAUSAS APARENTES}

El elemento simbólico de la crisis actual han sido las hipotecas de alto riesgo ("sub prime"), pues cuando se hizo evidente el incumplimiento creciente de estas, se revelaron también las importantes pérdidas de los inversionistas que las adquirieron (provenientes de todas partes del mundo). Sin embargo, un análisis más cercano permite establecer que fueron las burbujas en el sector inmobiliario $y^{-}$en el crédito bancario las que asentaron las raices de la crisis. A su vez hay quienes responsabilizan a la propia Federal Reserve System (FED) el hecho de haber mantenido las tasas de interés bajas durante periodos muy largos.

Hasta antes que la crisis se inició los precios de las viviendas crecieron sostenidamente debido al crecimiento económico de EE.UU., pero principalmente a la expansión del crédito a las familias (alcanzando cerca de 13 trillones de dólares americanos en conjunto). A partir de inicios del 2006 esta tendencia se revertió, pero ello no detuvo el crecimiento crediticio.

Efectivamente, un componente que propulsó más el crecimiento de los créditos fue el uso masivo de la titularización de hipotecas, lo que provocó que una gran masa de recursos provenientes de inversionistas de distinto origen geográfico y distinto apetito de riesgo se vuelquen a la adquisición de los valores titularizados que emitían los distintos vehículos de inversión formados para ese efecto (se estima que alrededor del $80 \%$ de las hipotecas fue cedida por los bancos a terceros). Fondos mutuos, Fondos de pensiones, Hedge Funds, Bancos, Bancos de inversión, entre otros, asignaron importantes sumas para estas inversiones. De esta forma una ingente cantidad de recursos recirculaba hacia

1 SOROS, George, The New paradigm for financial markets, 2008. 


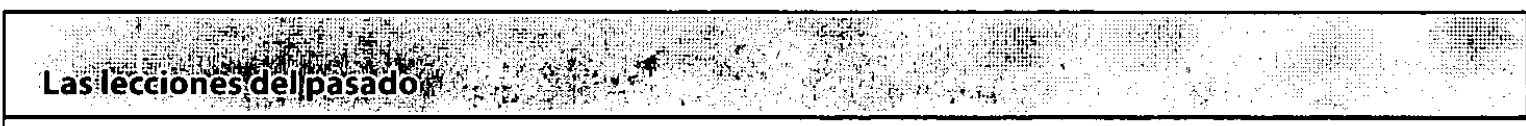

Para poder enfrentar apropiadamente la crisis vigente es importante tomar en cuenta las lecciones que las crisis financieras anteriores nos han dejado. Un breve repaso de las más importantes crisis los últimos 80 años nos permite notar que en su gestación se identifica alguna combinación de factores similares: especulación y la búsqueda de elevadas rentabilidades; insuficiente o mal orientada regulación, y la tardía o nula reacción del Estado para neutralizar los efectos:

- La Gran Depresión de 1929 se incubó en la creciente especulación en el mercado accionario durante buena parte de los años 1920's que fue propagada por la facilidad con que los bancos prestaban dinero a las personas para que inviertan en bolsa. Cuando la bolsa de desplomó, las autoridades se demoraron casi 3 años en aplicar medidas correctivas, lo que permitió que el PBI cayera en dos terceras partes y el desempleo alcance un $25 \%$ de la PEA. Los remedios posteriores incluyeron la creación de la Comisión de Valores (SEC), el Fondo de Seguro de Depósitos (FDIC), así como el Glass Steagal Act que impedía que los bancos puedan participar en el mercado de valores.

- Hacia 1985 la mayoría de los bancos de ahorro y crédito (similar a las mutuales) estaban quebrados. La desregulación iniciada en los años 1980's les permitía ingresar en nuevos tipos de operaciones; sin embargo su principal problema estribaba en que sus activos eran de largo plazo (hipotecas) y sus pasivos eran depósitos de mucho menor plazo. Los depósitos estaban garantizados por el Estado, y estos bancos no tuvieron reparos en competir agresivamente con bancos más grandes ofreciendo más altas tasas de interés.

- El 19 de octubre de 1987 las principales bolsas del mundo se desplomaron; así el Dow Jones cayó en $22 \%$. En un contexto de estancamiento en EE.UU., un temor generalizado de que las inversiones en bolsa y adquisición de compañías listadas estaban propiciadas por un fácil acceso al crédito ahuyentó a una buena parte del mercado ocasionando la referida caída.

- La crisis"dot.com": a fines de los años 1990's las compañías de Internet cautivaron a las bolsas y parecían representar un nuevo paradigma económico.

Una verdadera burbuja se configuró en los precios de las acciones de estas compañías; hasta que en marzo del 2000 la misma estalló de forma tal que el Indice de National Association of Securities Dealers Automated Quotation (NASDAQ) disminuyó en $78 \%$ para octubre del 2002. La inversión empresarial cayó fuertemente luego de esta crisis, lo que obligó a la FED a llevar la tasa de interés hasta $1 \%$ en la intención de reactivar la economía.

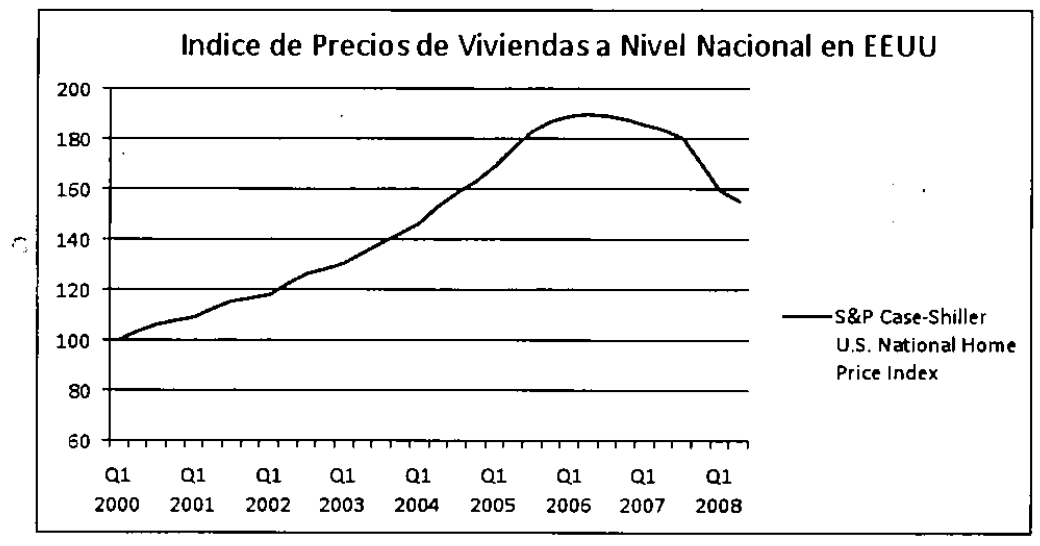




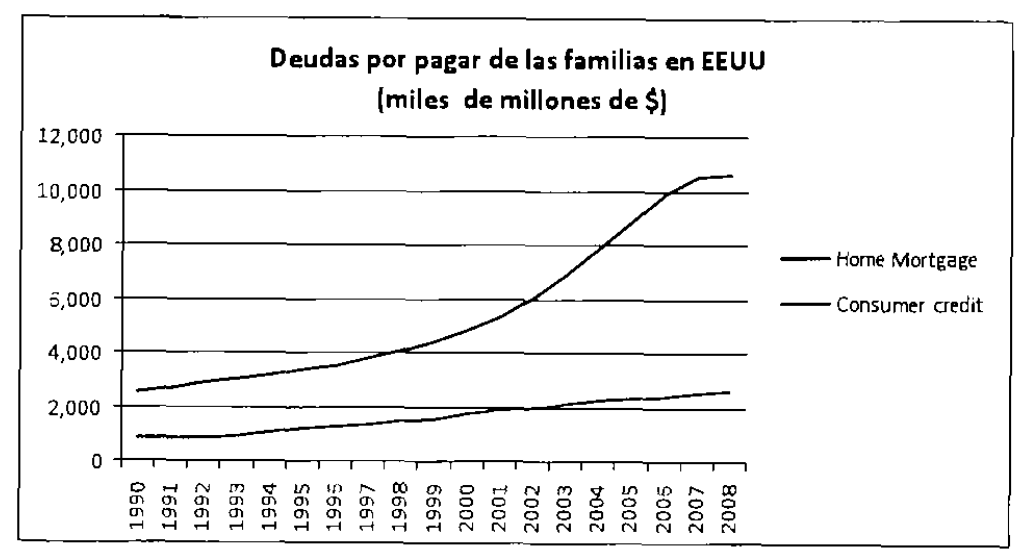

los bancos, los cuales otorgaban cada vez más préstamos, lo que de alguna forma indujo a que incursionen en los sectores sin historia crediticia o con capacidad de pago no demostrada; esto es sectores de mayor riesgo.

En adición a lo señalado algunos bancos promovían la constitución de los vehículos especiales de inversión. Algunos de ellos sencillamente se registraban en cuentas de orden fuera de su balance; en tanto que otros se diseñaban como nuevas entidades a las cuales usualmente se les concedia créditos para que adquieran las carteras titularizadas. Aun cuando se trataba de personas jurídicas distintas, existía una suerte de respaldo implícito en caso que tales vehículos entren en dificultades (riesgo reputacional que se convertía en un riesgo sistémico).

Para complicar más el panorama, en respuesta a las necesidades de los distintos tipos de inversionistas y de cobertura de riesgo de las instituciones participantes, se estructuraron productos financieros más complejos, que no permitían conocer cabalmente hacia donde se desplazaba el riesgo. De hecho muchos inversionistas no comprendian realmente las características de los instrumentos que adquirían y no tenían una clara apreciación del riesgo que enfrentaban. Se dejaban arrastrar por la euforia que los mercados de capitales suelen tener luego de varios períodos seguidos de crecimiento y ganancias.

Por un lado los valores titularizados se estructuraban de forma tal que repesentaban diferentes niveles de riesgo crediticio (segmentando por los tipos de deudores o por el plazo pendiente para su vencimiento), para atraer incluso a los inversionistas más arriesgados como los hedge funds. Más aun, muchas de las emisiones contenían un descalce de plazos, en razón que se emitían obligaciones para plazos relativamente cortos; aun cuando las carteras de crédito mantenían duraciones mas largas. Por su parte, las opiniones de las clasificadoras de riesgo, representaban el sello de garantía faltante pues otorgaban calificaciones de bajo riesgo, sin anticipar correctamente el problema potencial. El otro protagonista de esta alquimia financiera, fueron los "Credit Default Swaps (CDS)" que pretendian asegurarles a los bancos cubrirlos en caso que los deudores de los créditos incumplan.

De esta forma convergían entidades con distintas orientaciones y énfasis en la administración del riesgo:

Los bancos centrados en protegerse del riesgo crediticio; para lo cual tomaban los CDS (siglas en inglés, derivados de crédito que protegen contra la falta de pago).

Los inversionistas institucionales en el mercado de valores que buscaban obtener importantes ganancias en la negociación de hipotecas, especialmente las de alto riesgo. Su diversificación era cuando mucho a nivel geográfico en distintas áreas de EE.UU.

Las compañías de seguros ofreciendo coberturas al incumplimiento de las carteras de créditos bancarios. Basados en comportamientos históricos se consideraba que las carteras entran en 

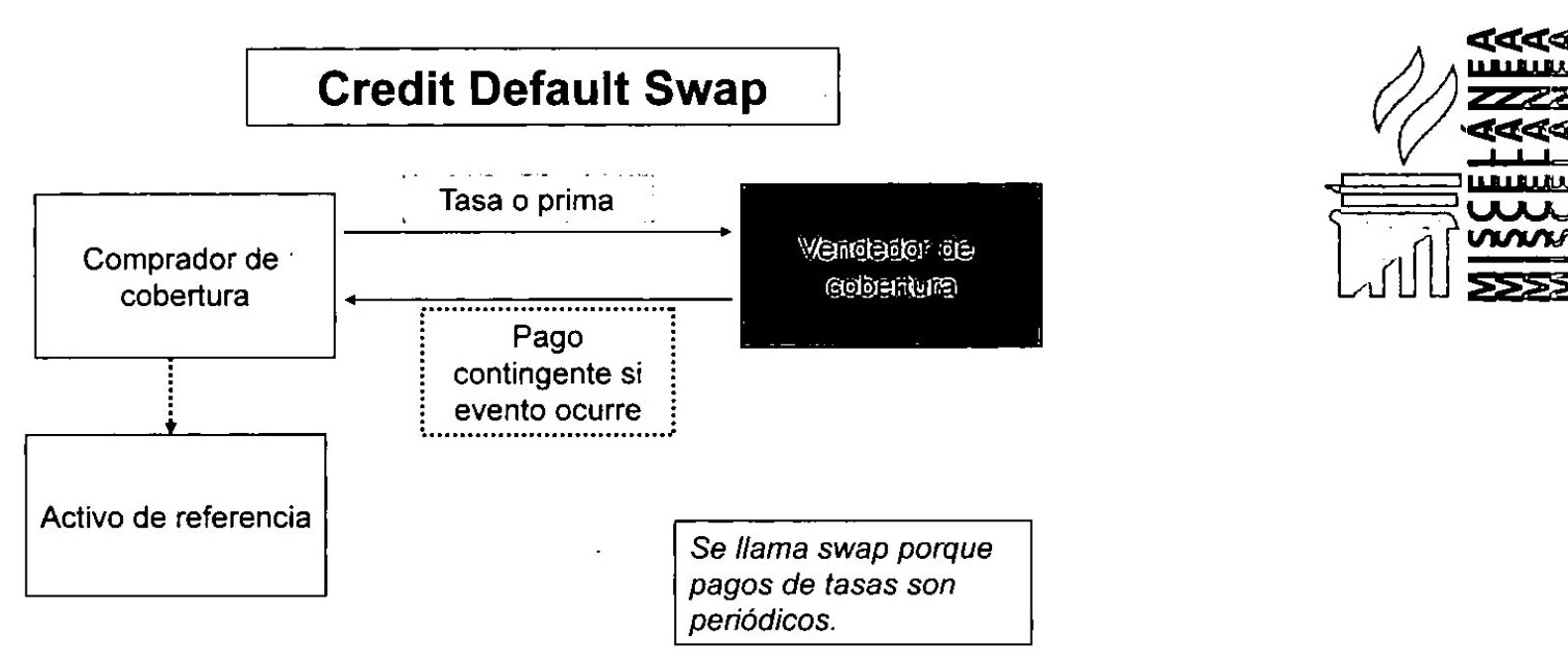

mora o dificultades en menores proporciones (baja probabilidad). Difícilmente estas compañías de seguros podían cubrirse a la vez del riesgo que asumian; por no existir productos financieros idóneos.

La estructura y los mecanismos antes descritos aparentaban funcionar bien dándole a cada quién su parte en las crecientes ganancias que se registraban. El gran supuesto tácito era que la economía y los mercados se mantenían al alza. ${ }^{2}$ Cuando las condiciones se volvieron adversas, empezando por el incumplimiento de las hipotecas sub prime y la desaceleración del mercado hipotecario, se hizo evidente que se habían establecido diversos canales que propagaban el riesgo sistémico. La caída de unos podía arrastrar la de otras entidades con relativa facilidad, con el agravante de una rápida internacionalización de los efectos debido a la activa participación de inversionistas institucionales de Europa, Asia y los demás países de mayor desarrollo relativo (contagio sistémico).

De otro lado, el exceso de confianza e inclinación a desdeñar los indicios preliminares de crisis también contribuyeron al escenario de crisis. ${ }^{3} \mathrm{Al}$ final, muchos inversionistas confiados, con exceso de optimismo y posiblemente mucha ambición, acumularon una buena cantidad de "activos tóxicos" vinculados a las referidas hipotecas cuyas probabilidades de repago son muy reducidas. Los bancos facilitaron el proceso procurando sus propias ganancias. Nadie se preocupó por evaluar el riesgo conjunto y proteger los intereses de los inversionistas finales, las personas. ${ }^{4}$

Es importante notar que diversos factores contribuyeron a la opacidad de los mercados financieros relacionados principalmente con la negociación de hipotecas; impidiendo así que se detectara la magnitud del problema que se estaba gestando. Por un lado, buena proporción de las transacciones se realizaban fuera de los mercados regulados ("over the counter") con la participación de múltiples inversionistas institucionales que supuestamente saben velar por sus propios intereses, e indirectamente proteger a aquellos que les confiaron sus fondos. De otro lado la titularización involucra a diversos participantes, cada uno con su propia responsabilidad,

2 Una respuesta de Chuck PRINCE, CEO de Citigroup, en una entrevista al "Financial Times" a mediados del 2007, refleja muy bien esta percepción: "Cuando la música se detenga en términos de liquidez, las cosas se complicarán. Pero en tanto la música siga sonando tienes que pararte y bailar. Nosotros estamos aún bailando".

3 MOHAMED, El-Erian, When markets collide, 2008.

4 Alan GREESPAN en su testimonio al Congreso a fines de octubre del 2008 señaló que había cometido un error al creer que los bancos actuando en su propio interés harían lo necesario para proteger a los accionistas y las instituciones. 
sin que necesariamente alguno en particular mantenga la visión conjunta de las distintas estructuraciones que se iban montando. También añadieron su cuota las prácticas contables (vía las cuentas fuera de balance) de las instituciones financieras que no permitían conocer su verdadero grado de exposición al riesgo.

\section{LOS EVENTOS Y LA BÚSQUEDA DE LA SOLUCIÓN}

El temor a las burbujas ha existido desde tiempo atrás por parte de los analistas, relacionándolo al mercado hipotecario, al mercado crediticio e incluso al mercado de valores. Sin embargo no fue sino hasta los primeros meses del año 2007 que se registraron los primeros hechos relevantes que reflejaban la potencial crisis financiera. Para muchos fueron las dificultades de dos fondos de cobertura ("Hedge Funds") de Bearn Stearns en agosto de ese año, las que empezaron a marcar la preocupación. Tales fondos habian justamente invertido en hipotecas sub-prime, y sus falencias motivaron finalmente que Bearn Stearns sea adquirida (con auspicio de la FED) por JP Morgan Chase en marzo del 2008. El otro hito fundamental en esta cadena de acontecimientos fue la quiebra de Lehman Brothers en septiembre del 2008, momento en el cual la confianza de los mercados fue debilitada fuertemente. Los sucesos aún se siguen desencadenando y la tabla adjunta "La crisis en los hechos" describe los principales eventos hasta ahora ocurridos.

Los hechos muestran una seguidilla de situaciones de dificultades de distantes entidades financieras (pasando por el rescate de Fannie Mae y Freddie Mac y la adquisición de Merryl Lynch por parte del Bank of America); que fueron obligando paulatinamente a las autoridades financieras a brindar apoyo bajo diversos mecanismos, empezando con las facilidades de liquidez hasta el aporte de recursos para que se
De esta forma los reguladores y demás supervisores financieros ingresaban en terrenos hasta ahora desconocidos y rechazados por ellos; flexibilizando marcadamente incluso sus herramientas de política a fin de prevenir el riesgo sistémico (como cuando la FED extendió facilidades de liquidez a los bancos de inversión; cuando estos mecanismos históricamente solo han atendido a los bancos comerciales). Por ello, sus decisiones fueron en algunos casos erráticas (los europeos reaccionando más rápido que los EEUU donde estaba la raíz del problema), tratando incluso casos asimilables de forma diferente. Así mientras Bearn Stearns o AIG recibió el auxilio debido para no quebrar; no sucedió lo mismo con Lehman Brothers, donde se trató enseñar al mercado que el riesgo moral (aquel de tomar riesgos en exceso con la pretensión que el Estado lo cubra) se castiga. Esto último resultó en un error de cálculo pues fue finalmente el detonante para que los mercados muestren todos sus temores y se manifieste abiertamente la crisis. Al final el concepto de "demasiado grande para quebrar" pareciera ser el que siga dictando la norma.

Es interesante notar la manera como los mercados fueron interpretando los acontecimientos. El mercado accionario fue declinando paulatinamente desde el segundo semestre del 2007 (acumulados de pérdida entre 50 y $70 \%$ ), cuando las primeras señales de la crisis hipotecaria emergieron. Las pérdidas a la fecha se estiman en unos 8 trillones de dólares.

Por su parte el mercado crediticio, a juzgar por las tasas de interés más representativas, recién denotaron los efectos de la crisis hacia marzo del 2008 cuando las tasas bancarias empezaron a marcar claras distancias de las tasas de la reserva federal, las cuales estaban mas bien orientadas a proporcionar alivio a las familias con deudas hipotecarias y evitar también que le economía entre en recesión.

Las reacciones verificadas desde fines de septiembre del 2008 acentuaron las características de crisis de liquidez o "credit crunch" que ahora enfrentamos. En efecto los bancos optaron por 

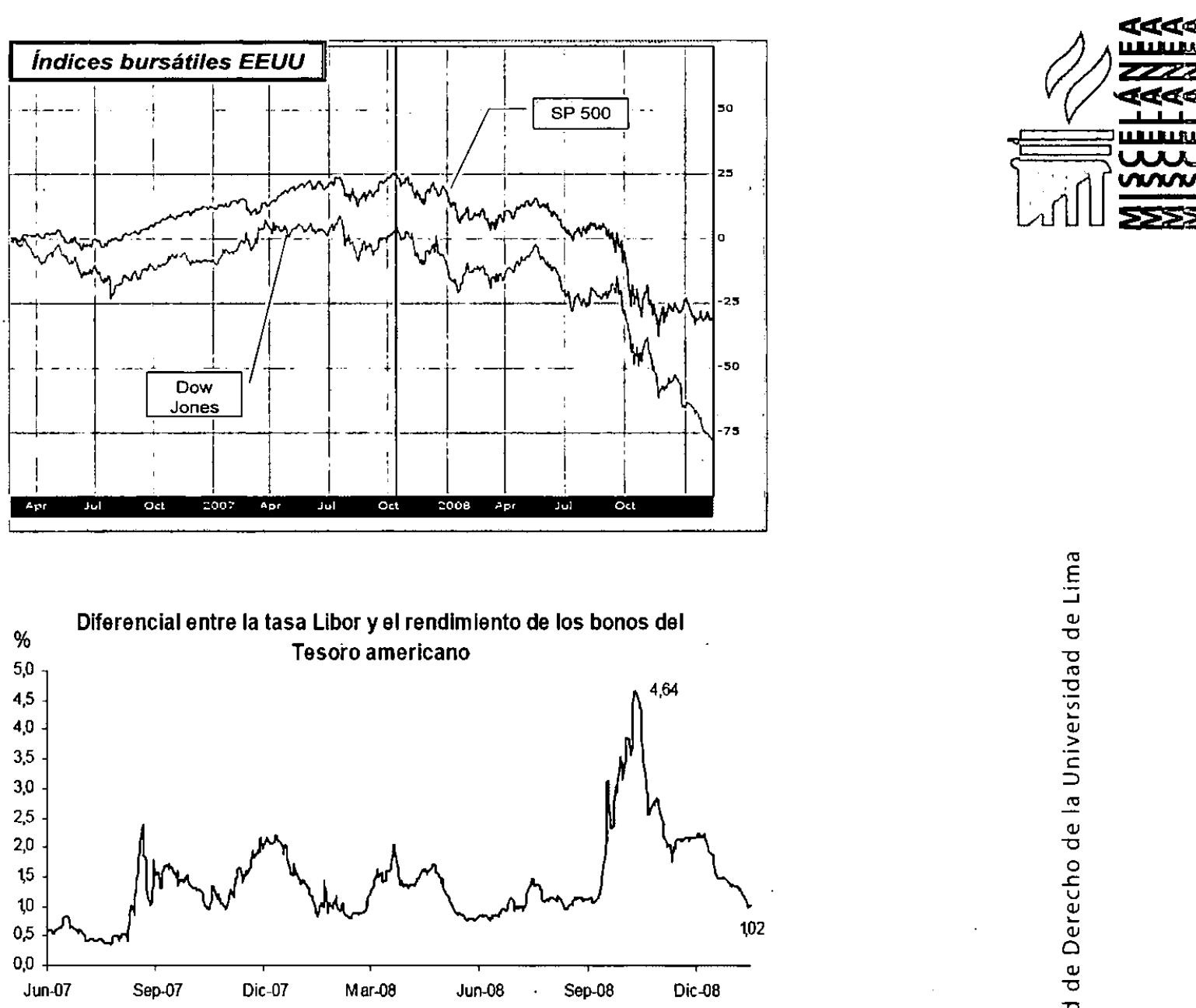

cerrar o limitar.los créditos que otorgaban a fin de aliviar su posición de liquidez, debido a las pérdidas por los créditos hipotecarios; a su vez urgían a sus deudores a cancelar sus deudas y cerrar sus líneas de crédito, lo cual los volcaba a los mercados de dinero a buscar los recursos necesarios. Si bien los diferenciales de tasas se redujeron ostensiblemente, desde entonces, ello no ha modificado la actitud de los bancos de limitar al máximo la concesión de créditos.

Los distintos inversionistas institucionales, que sufrían el impacto de las pérdidas por inversiones en valores hipotecarios, buscaban salir de sus posiciones y reasignaban sus portafolios en la típica estrategia de "fly to quality" (búsqueda de calidad). Los mercados de créditos se endurecieron (altas tasas y escasa liquidez) y las bolsas se desplomaron.

PETRÓLEO WTI (USS por barril)

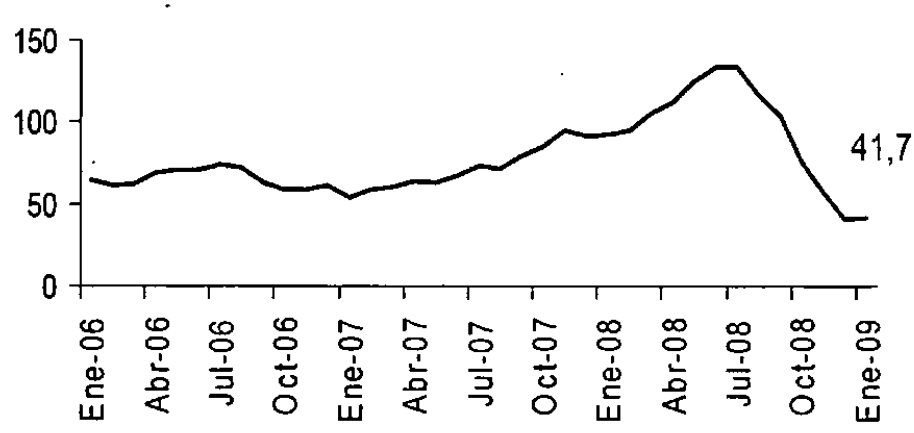


De otra parte, los precios de los commodities también empezaron a declinar, especialmente el petróleo que luego de estar a US\$ 144 el barril ha caído por debajo de los US\$ 40 en el mes de febrero; en razón que perdió atractivo como alternativa de inversión (las inversiones especulativas en este mercado crecieron significativamente los últimos cuatro años) y porque la percepción de posible recesión en diversos países aumentaba. Lo bueno de ello es que las presiones inflacionarias se veían amenguadas; pero lo malo es que a países exportadores de materias primas como Perú las condiciones se les empezaban a revertir.

5 Troubled Asset Relief Program. profundo y líquido del mundo; donde además se pueden encontrar instrumentos de refugio menos riesgosos como son las obligaciones del Tesoro americano. Por ello los capitales fluyeron más bien hacia EE.UU. apreciando así al dólar. Ello permitirá que el gobierno americano pueda seguir aprovechando el señoreaje del dólar y seguir acumulando déficits. ¿Por cuánto tiempo? Eso está por verse.

Los sucesos urgieron a las autoridades de diferentes paises a armonizar sus planes de acción; y es por ello que los G7 anunciaron acciones coordinadas para el manejo de la crisis. La magnitud de la debacle se iba haciendo cada vez más notoria, lo que a su vez obligaba a poner una mayor cantidad de recursos para salvar al sistema. Un punto culminante se alcanzó en octubre del 2008 con la aprobación del paquete de rescate denominado TARP ${ }^{5}$ en EE.UU. por un monto de US\$ 700 billones que se irá aplicando gradualmente. Sin embargo, como era previsible los recursos resultaron insuficientes, lo que conllevó a la aprobación de un nuevo paquete de estímulo por US\$ 787 billones en febrero del 2009.

A pesar de los esfuerzos, la pérdida de confianza es lo que ha primado en el comportamiento de los mercados desde fines de septiembre del 2008. A la hecatombe financiera se ha unido la recesión en EE.UU. (y no tan solo una ralentización como muchos sostuvieron hasta ahora), en algunos países europeos (Inglaterra ya reveló sus proyecciones de caída de producto) y en

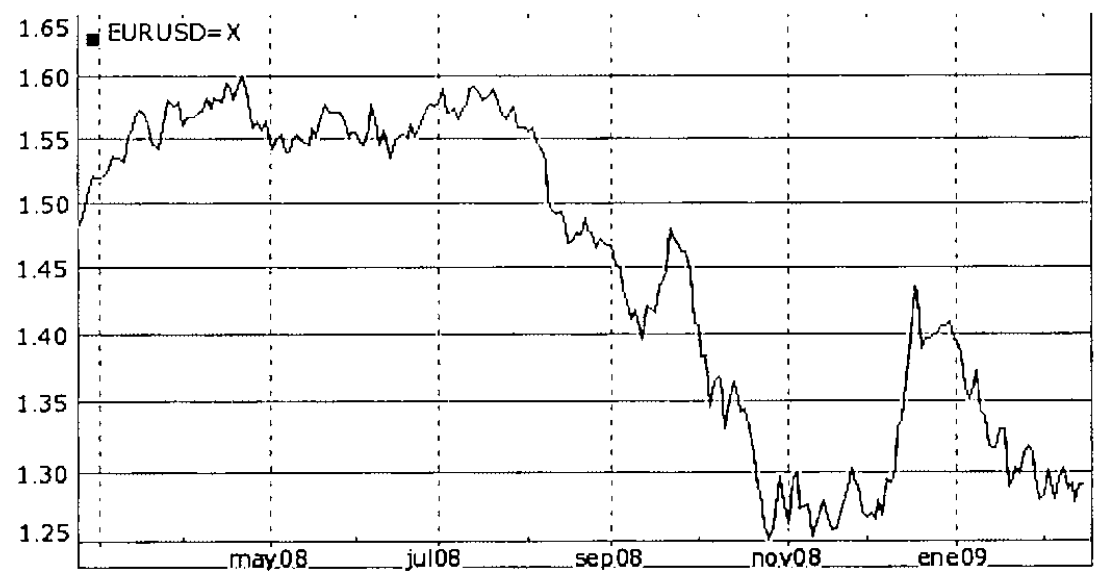


países asiáticos como Japón. Pocas dudas deben quedar al respecto pues las pérdidas se reflejan en el valor de las viviendas (entre 30 y $40 \%$ ) y de los fondos mutuos ( $50 \%$ de las familias americanas tienen fondos mutuos). Los principales Índices bursátiles en EE.UU. han retrocedido no menos de $50 \%$ desde su punto máximo. Las familias americanas han perdido buena parte de sus patrimonios y por tanto vienen reacomodando sus patrones de consumo, disminuyendo sus gastos; ello a su vez provoca disminución del producto y aumento del desempleo.

En los años previos, EE.UU. había logrado compensar el movimiento adverso de algunos componentes de su gasto agregado por la vía de las exportaciones; y por eso el dólar se mantuvo bajo. Con el dólar repuntando ello ya no es posible.

\section{PERSPECTIVAS DEL PANORAMA INTERNACIONAL}

Es muy complejo prever cuánto durará esta crisis y cuál será la magnitud de su impacto. Lo cierto es que aún no hemos tocado fondo y pasará un buen tiempo antes de que recuperemos los niveles previos a la crisis. Varias opiniones influyentes han advertido ya de la severidad del problema. Como cuando Greenspan la denomina "tsunami crediticio que sólo ocurre cada siglo"; o cuando Bernanke confiesa un panorama sombrío para la economía america- na, o en la ocasión que Paul Krugman (premio Nóbel de economía) advierte que los paquetes de rescate son insuficientes para la dimensión de la recesión, o incluso cuando Carlos Slim (el empresario más rico de México y uno de los tres más ricos del mundo) anticipa una severísima recesión en su país.

Los esfuerzos desarrollados son sin duda importantes, tanto a nivel de los dos paquetes de rescate financiero aprobados en EEUU como los acuerdos de políticas armonizadas entre los países más avanzados (por ejemplo, G-7 ó $\mathrm{G}-20$ ); pero existen varias razones para concluir que aún no se acercan al objetivo de controlar a la crisis. En primer término los recursos destinados lucen todavía escasos frente a las pérdidas acumuladas por efecto de la crisis (no menos de 2.2 trillones de dólares, según el estimado del Fondo Monetario Internacional (FMI) a enero del 2009). De otro lado, han habido indefiniciones y controversias en relación a la forma como se deberían aplicar los recursos de los paquetes de rescate en EE.UU., alternándose variantes como:

- Adquisición de activos tóxicos a los bancos comprometidos en pérdidas;

- Capitalización de bancos por medio de compra de acciones preferentes;

- Compra de papeles comerciales para darle liquidez a las empresas;

- Financiar la adquisición de bancos pequeños por parte de bancos más grandes;

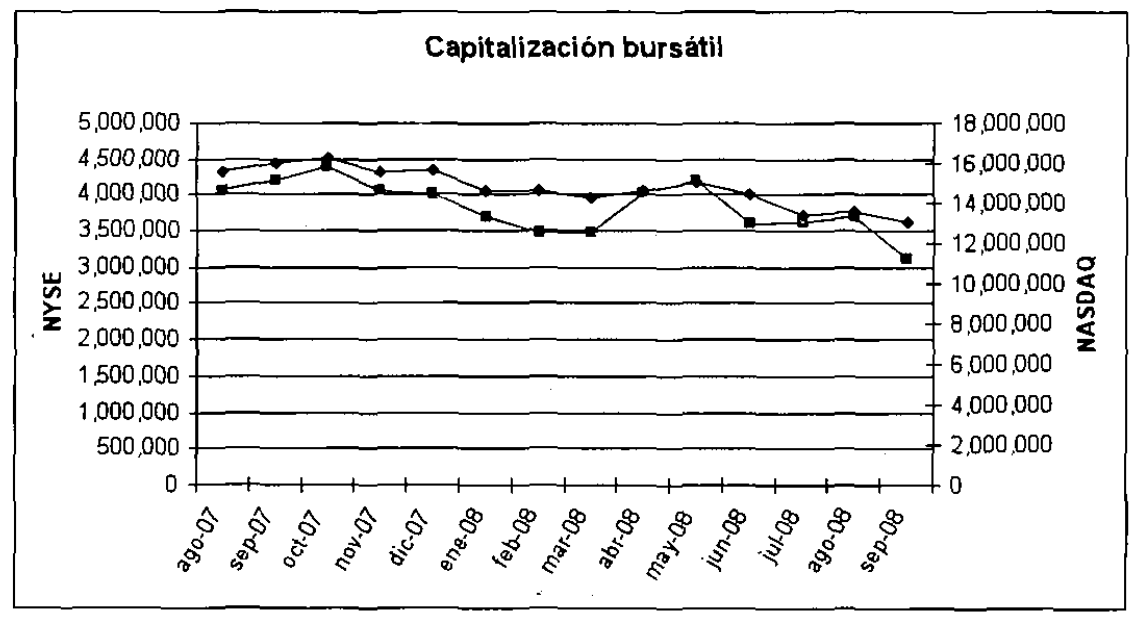


- Ayuda a los bancos que concedan facilidades de refinanciamiento a los deudores amenazados; por la ejecución de sus hipotecas; y

- Auxilio financiero a las principales compañías automotrices

De hecho, no todas las alternativas han sido acogidas positivamente por los contribuyentes estadounidenses; y posiblemente otras alternativas de uso emergerán en este proceso que parece no tener la ruta clara. Estas medidas han sido acompañadas de otras definiciones como la exigencia de restringir las bonificaciones a los ejecutivos de las empresas beneficiadas con los recursos del rescate. Esto último se relaciona con los reclamos por la falta de ética (y exceso de ambición) observada por los banqueros provocadores de la crisis.

En adición a lo señalado, el impacto de la crisis transcendió el ámbito financiero y se trasladó al sector real; expandiendo su impacto negativo y acrecentando la profundidad del problema. No habrá salida de la crisis si las economías se mantienen en recesión como las que ya se encuentran en EE.UU., la zona Euro y Japón, por citar lo más notorio. Las proyecciones del año 2009 (según el World Economic Outlook del FMI) lucen sombrías en tanto serán los países emergentes como China, India y otros como Perú, los únicos que crecerán pero definitivamente por debajo de lo registrado en los años previos. Su crecimiento conjunto no compensará las pérdidas de producto de los demás países de mayor envergadura económica.

Por ahora se piensa que la recuperación empezaría en el 2010, pero es todavía temprano para poder afirmar ello. Al respecto, recientes estudios de las crisis financieras desde la Gran Depresión recuerdan que en promedio las caídas de $\mathrm{PBI}$ se revierten en no menos de dos años, las de empleo en no menos de cuatro años, las caídas de los precios de las acciones en no menos de 3.5 años y las caídas de los precios de las casas en no menos de seis años. ${ }^{6}$ En base a ello debemos deducir que la recuperación tardará un lapso de años; sin olvidar la naturaleza inédita de la crisis actual.

Más preocupante es el hecho de que al gobierno americano se le podrían estar agotando las variantes de política económica. De un lado la tasa de interés de referencia que fija la FED está prácticamente en cero; en tanto que el déficit fiscal alcanzaría un nivel históricamente muy elevado el presente año (más de $8 \%$ del PBI contra un promedio de $2.5 \%$ los últimos cuatro años). Los paquetes de rescate significan mayor gasto y la recesión implica menor recaudación tributaria agravando la brecha.

Cabe además preguntarse qué ocurrirá luego que la crisis sea controlada, y la economía tienda a recuperarse y los mercados financieros reviertan sus pérdidas. Muy posiblemente la factura de la ingente inyección de recursos y el enorme déficit fiscal de EE.UU. signifique finalmente la caída del dólar, de acuerdo a lo que los fundamentos económicos sustentarían. ¿Será la mejor estrategia de mediano plazo refugiarse en el dólar?

El entorno internacional será definitivamente distinto luego de la crisis, no solo porque el propio presidente Obama ha advertido que los responsables serán investigados y sancionados; sino porque el consenso reclama un rediseño del sistema financiero global; como concluyó el último Foro de Davos, y que implicaría posiblemente regulaciones y esquemas de supervisión más estrictos como ocurre siempre luego que una crisis importante se produce (lo más reciente fue el Sarbanes - Oxley Act luego del escándalo de ENRON y otras grandes corporaciones).

Por lo pronto, la reversión de la situación necesita que se recobre la confianza de los inversionistas y consumidores; lo cual solo podría acontecer cuando algunos indicadores económicos y financieros empiecen a mejorar

REINHART, Carmen y ROGOFF, Kenneth, The aftermath of financial crises, 2008. 
y el mercado tenga una lectura positiva de ellos. Eso, por ahora, no parece una posibilidad cercana.

\section{LOS EFECTOS DE LA ECONOMIA PERUANA}

La crisis en curso encuentra a Perú en una posición estable y más sólida que la gran mayoría de los países. Perú ha venido creciendo durante ocho años seguidos, ha acumulado RIN (Reservas Internacionales Netas) por el equivalente de más de 15 veces las importaciones del país; ha reducido y reperfilado su deuda pública y ha configurado un sistema financiero con mayor solvencia. Sin embargo, estando claros que se trata de una crisis globalizada, Perú no se librará de su impacto.

Podemos anticipar que la crisis impactará la economía peruana a través de los siguientes canales:

- Exportaciones: algunos de nuestros principales socios comerciales (empezando por EE.UU. y la Zona Euro) entraron en recesión disminuyendo la compra de nuestros productos, e igualmente los precios de nuestras exportaciones tradicionales disminuirán. Los primeros indicios señalan que el sector minero y el sector textil han reducido de manera importante el valor de sus ventas, lo que ha conllevado a una pérdida de puestos de trabajo.

- Restricción de créditos: los bancos internaciones ya limitaron sus líneas de crédito y encarecieron las existentes; y ello a pesar de los flujos de liquidez recibidos en el paquete de rescate. De esta forma los bancos locales ven encarecida una de sus fuentes de financiamiento; que aun cuando no sería importante en general, debe recordarse la importante presencia de la banca extranjera en nuestro pais; por tanto ello motivaría el encarecimiento del crédito a nivel local.

- Caída en las cotizaciones bursátiles: el contagio que irradia una crisis global hace que la incertidumbre prevalezca por encima de cualquier buen fundamento que puedan tener nuestras empresas. Ello ha venido justamente registrándose en nuestra bolsa en donde sus índices han disminuido más de 40 $\%$ en el mes de Octubre, y más de $60 \%$ en el año 2008. Los principales afectados son los Fondos de pensiones, y por supuesto los afiliados que son los propietarios de estos. Como punto más álgido, hasta septiembre del 2008 dichos Fondos habían perdido US\$ 5 mil millones (como $15 \%$ de su valor).

- Remesas: una creciente proporción de familias peruanas goza del beneficio de las remesas que envían sus familiares del exterior (se proyectaba que alcanzarían los US\$ 3 , 000 millones), lo que les permitía una mejor capacidad de gasto. La recesión en EE.UU. y Europa reducirá este flujo de recursos.

- Menor inversión extranjera: De un lado la estrategia del "fly to quality" inducirá a una menor presencia de los inversionistas institucionales en los mercados emergentes; y de otro lado todas aquellas empresas extranjeras que dependían para su fondeo del mercado internacional y de sus empresas matrices, verán recortadas estas posibilidades, debiendo reprogramar varias de sus inversiones. Las proyecciones del Banco Central de Reserva del Perú (BRCP) para el 2009 reflejan que la inversión privada seguirá creciendo por la inercia de compromisos asumidos anteriormente, pero definitivamente desacelerará su ritmo de crecimiento.

El gobierno no se ha quedado inactivo y ha lanzado su propio plan anticrisis enfocándolo hacia las obras de construcción en los sectores de menos recursos y hacia la descentralización del gasto. Las principales dudas residen en la escasa capacidad gerencial de los gobiernos regionales, que podrían atentar contra las buenas intenciones del gobierno. Por su parte el BCRP ha adoptado medidas para incrementar la liquidez del sistema financiero vía la reducción de encaje y operaciones de corto plazo (v.gr. reportos). A pesar de ello, aún cuando se proyecta que Perú seguirá creciendo en el año 2009, la tasa será cuando mucho de $5 \%$ de crecimiento real, con reducciones tanto en la demanda

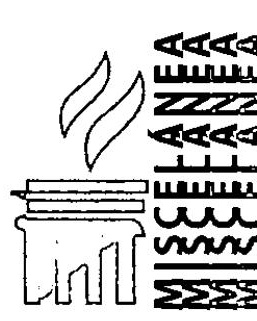

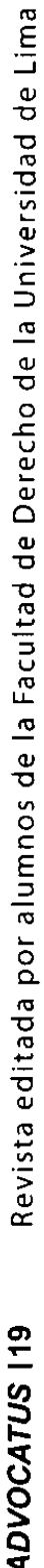


interna como en las exportaciones. Todos los sectores económicos verán reducidas sus tasas de crecimiento, y se espera que el liderazgo lo asuma el sector construcción.

Debemos tener presente que las defensas de que ahora dispone la economía peruana se irán menoscabando en la medida que la crisis se prolongue. Un menor crecimiento generará menos recaudación tributaria (como ya se empezó a evidenciar) y ello reduce la disponibilidad de recursos para el gasto público. En una siguiente etapa se debería recurrir al endeudamiento, sobre el cual existe un margen de holgura y que nos podría permitir manejar la crisis un tiempo adicional, pero paulatinamente a un costo creciente. El rol contracíclico del gobierno es importante pero tiene sus propias limitaciones.

Por otra parte, teniendo en cuenta lecciones del pasado, que revelan que las crisis se agudizan cuando el sector financiero se ve involucrado, se considera que para que el impacto en el Perú no resulte dramático se dependerá en primer término de la oportuna reacción de las autoridades (especialmente el $B C R$ ) en cuanto las necesidades de liquidez apremien. En adición a ello, para evitar mayores consecuencias en nuestro crecimiento económico, se dependerá de la capacidad de mantener exportaciones en alza hacia los demás países sin problemas aparentes de recesión (como China); de sostener el ritmo de inversión privada (a pesar del posible freno en la inversión extranjera) y a través de ello preservar los niveles de consumo privado. El escenario a enfrentar es bastante adverso y de compleja administración.

\section{EL CAMINO POR DELANTE}

En la perspectiva que estamos viviendo una de las más grandes crisis de la era moderna, se puede vislumbrar que algunos factores mantendrán su vigencia más allá del momento actual, por lo que conviene identificarlos e intentar comprender sus alcances potenciales:

- Nueva frontera del ámbito público-privado: las decisiones de capitalizar las instituciones financieras en problemas financieros han provocado que el Estado vaya convirtiéndose en un accionista principal de estas; $y$ aun cuando su participación sea temporal, es previsible que condicionará su salida a la satisfacción de determinados estándares. En otros casos, difícilmente se dejará en manos privadas algunas entidades que son claves para el desenvolvimiento del mercado (como es el caso de Fannie Mae o lo que devenga de ella).

- Una nueva arquitectura regulatoria: todas las grandes crisis ponen en movimiento el péndulo por el cual luego de una etapa donde prevalecía la desregulación o la mayor libertad, se pasó al otro extremo con mayores controles y exigencias. Los reguladores no querrán dejar nada al azar y buscarán, en lo posible, que todas las transacciones financieras en los distintos segmentos del mercado sean reguladas o al menos sea posible hacerles seguimiento. Ello derivaria en una estrategia donde los distintos mercados (bancario, capitales, seguros, etc.) sean regulados bajo esquemas integrados; lo que a su vez significará el establecimiento de esquemas con la integración de funciones de los reguladores. En ese mismo orden de ideas, la innegable globalización de los mercados financieros motivará acciones más concertadas y planificadas entre los entes supervisores de distintos países.

Concentración: Una de las exigencias que posiblemente prevalecerá es que se requerirá mayor patrimonio y respaldo a quienes participen en los mercados financieros. Ello implicará la fusión de distintas entidades, y la desaparición de otros.

Un sistema financiero remozado: el mapa de participantes de los mercados financieros cambiaría de forma importante. A la desaparición verificada de los bancos de inversión; se unirán otro tipo de exigencias a ciertas estructuras como son las titularizaciones, que posiblemente pasen a un ámbito más regulado. Distintas nuevas ideas serían discutidas intensamente como son la formación y administración de derivados; e incluso la 
aplicación del precio de mercado o valor razonable a todos los actores del mercado.

- Prevalescencia del dólar y de su mercado de capitales: Tomaría algunos periodos antes que el dólar pudiera perder su predominancia como principal moneda de cambio internacional. Sus contendores, como el euro están atravesando similares dificultades que hacen remoto prever una sustitución de primacía. De otro lado, el mercado de capitales de EE.UU. mantendría, al menos en el mediano plazo su supremacía; mientras los inversionistas institucionales necesiten buscar destinos alternativos y los demás mercados no ofrezcan la profundidad y diversidad requeridas. El principal reto del dólar son los desequilibrios internos que mantiene la economía americana y que podrían terminar depreciando significativamente esa moneda.

- El nuevo rol de los países emergentes: los países emergentes liderados por el grupo denominado BRIC (Brasil, India, Rusia, China), especialmente China e India, han registrado altas tasas de crecimiento que las han permitido acumular crecientes reservas. Estos países conjuntamente con los países petroleros influirán de manera decidida la forma como se configurarán los mercados financieros del futuro al definir las inversiones y destinos donde aplican los recursos. Uno de los vehículos de creciente notoriedad en este respecto son precisamente los Fondos Soberanos ("Sovereign Wealth Funds") que in- cluso han dado señales de preferir inversiones menos ortodoxas (desde inversiones directas en proyectos energéticos en países distintos al suyo hasta rascacielos en Manhatan).

Tal vez es aún prematuro para identificar todos los cambios que se gestarán, pero sin duda los mencionados estarán en el orden del día. Una acotación final: a pesar de la crisis y todas las pérdidas de riqueza que conllevará; existe una ingente cantidad de recursos financieros acumulados en el mundo, los cuales igualmente necesitarán un destino de inversión y sobretodo hacer rentables sus inversiones. Este incentivo presionará constantemente al mercado y las posibilidades de llegar a situaciones como la actual estarán siempre presentes, en razón que existirá ambición de ganar e innovación financiera constante. Ello no es malo per se, pero es imprescindible mejorar nuestra arquitectura financiera, y en particular la capacidad de las entidades de conocer y administrar sus riesgos.

En resumidas cuentas, la crisis sigue su curso, los mercados lucen pesimistas, a pesar del nuevo gobierno en EE.UU. y de los esfuerzos de rescate adoptados. Falta para tocar piso, y ello seguirá afectando a las economías, incrementando sus pérdidas. Solamente la perseverancia y la consistencia de las políticas que se apliquen nos sacarán adelante. En algún momento (definitivamente no en el presente ạno) la confianza empezará a recuperarse y las tendencias se revertirán. Precaución y tolerancia es por ahora la mejor receta.

\section{La srisisenloshechos Wryting}

\section{MARZO 2007}

08: Una de los mayores constructores de EE.UU., D.R. Horton, advierte que sufrirá grandes pérdidas debido a la caída del mercado de hipotecas subprime.

ABRIL 2007 -

02: La financiera estadounidense New Century Financial Corporation, especializada en hipotecas de alto riesgo, presentó un pedido de protección por bancarrota.

JULIO 2007

31: Bear Stearns, impide que los clientes retiren dinero en efectivo de un hedge fund, diciendo que se 
ha desbordado por las solicitudes de redención.

\section{AGOSTO 2007}

09: El Banco Central Europeo vuelca al mercado unos US\$120,000 millones.

13: La Reserva Federal de EE.UU. inyectó US\$2,000 millones, luego que el Banco Central Europeo (BCE) desembolsara US\$65,000 millones y el Banco Central de Japón otros US $\$ 5,000$ a su mercado.

21: El número de las inscripciones para ejecuciones de viviendas en los EE.UU. aumentó en julio en $93 \%$ en comparación con el mismo mes del año pasado.

\section{SETIEMBRE 2007}

14: El Banco de Inglaterra anuncia que brindará apoyo financiero al banco Northern Rock, uno de los mayores prestamistas de dinero para hipotecas.

18: Reserva Federal de Estados Unidos redujo las tasas de interés, en medio punto porcentual. La tasa interbancaria diaria bajó al $4,75 \%$, desde el 5,25\%.

\section{OCTUBRE 2007}

01: UBS informó que depreciaciará de sus activos por US\$ 3.400 millones como consecuencia de malos resultados en inversiones en créditos hipotecarios en EE.UU.

18: La cotización del dólar volvió a desplomarse a sus mínimos históricos contra el euro, ante renovados temores de una desaceleración en la economía de EE.UU.

30: El presidente de Merrill Lynch, Stan O'Neal, renunció a su cargo después de que la compañía reconociera que sus deudas incobrables alcanzan los US\$ 7,900 millones.

31: La Reserva Federal de EE.UU., rebaja la tasa de interés clave, quedando en 4,5\%.

\section{NOVIEMBRE 2007}

05: Citigroup anuncia una caída del $57 \%$ en sus beneficios trimestrales, propiciada por las pérdidas en el mercado de los préstamos de alto riesgo. Su director, Charles Prince, renuncia a su cargo

09: Wachovia, la cuarta institución financiera en importancia de EE.UU., anuncia pérdidas por unos US\$ 1,100 millones en octubre.

12: Citigroup, Bank of America y JP Morgan Chase anuncian plan reactivador del mercado crediticio.

27: El precio de las viviendas en EE. UU. baja drásticamente en el tercer trimestre, ubicándose en el menor nivel en 21 años.

\section{DICIEMBRE 2007}

06: George W. Bush anuncia un plan para congelar los intereses de algunas hipotecas de alto riesgo.

10: UBS, anunció nuevas pérdidas por US\$10,000 millones en el valor de sus activos financieros.

11: La Reserva Federal baja las tasas de interés al 4,25\%.

18: Los bancos centrales de EE.UU., la Unión Europea y el Reino Unido anunciaron medidas para ayudar al sector bancario a hacer frente a la crisis crediticia. Junto con el Banco Nacional Suizo y el Banco de Canadá, hicieron público un plan para inyectar US\$100,000 millones en fondos de emergencia.

19: Morgan Stanley reveló pérdidas de US\$ 9,000 millones asociadas a los problemas del mercado inmobiliario estadounidense. Anunció la venta de $10 \%$ de sus acciones al gobierno chino.

\section{ENERO 2008}

04: EE.UU. registró en diciembre la tasa de desempleo más alta en dos años.

15: Citigroup colocará más de US\$18,000 millones en cuentas incobrables, al haber estado altamente expuesto a malos préstamos en el mercado hipotecario.

17: Merrill Lynch, anuncia pérdidas netas al finalizar 2007 de US\$ 7,800 millones.

22: La Reserva Federal de EE.UU. recorta las tasas de interés al 3,5\%.

30: La Reserva Federal recorta su tasa clave de interés de 3,5 a 3\%. 


\section{FEBRERO 2008}

06: Las acciones en Wall Street sufrieron sus peores pérdidas en casi un año.

10: Los ministros de Finanzas y gobernadores de los bancos centrales del G7 advierten sobre el empeoramiento de la economía.

13: Las pérdidas sufridas por las empresas japonesas financieras debido a la crisis hipotecaria en EE.UU. se han duplicado en los últimos tres meses de 2007.

\section{MARZO 2008}

11: Reserva Federal de Estados Unidos, el BCE y los bancos centrales del Reino Unido, Canadá y Suiza intentan aliviar las condiciones en los mercados de crédito, con una ayuda de US\$200 mil millones.

17: Bear Stearns fue adquirido por JP Morgan Chase por US\$240 millones.

\section{ABRIL 2008}

6: El director del FMI, Dominique Strauss-Kahn, afirma que se requiere la intervención gubernamental a nivel global para mitigar la actual crisis de los mercados financieros.

\section{MAYO 2008}

22: UBS lanzó una emisión de derechos preferentes de US\$15,500 millones para cubrir parte de los US $\$ 37,000$ millones en pérdidas de activos ligados a deudas hipotecarias.

\section{JUNIO 2008}

19: Dos miembros del banco Bear Stearns se les acusa de conocer y no informar a los inversores sobre los problemas de los fondos de inversiones subprime.

\section{JULIO 2008}

13: Indy-Mac, uno de los principales bancos hipotecarios de EE.UU., fue intervenido por el gobierno.

15: Las autoridades financieras intervinieron para ayudar a Fannie Mae y Freddy Mac.

\section{AGOSTO 2008}

14: Informan que las economías de los 15 paises de la eurozona se contrajeron un $2 \%$ entre abril y junio.

\section{SEPTIEMBRE 2008}

14: Lehman Brothers se declara en bancarrota por sus pérdidas en el sector hipotecario.

17: AIG recibe US\$85.000 millones en préstamo de la Reserva Federal, lo que significa que el gobierno asumirá casi el $80 \%$ del control de la empresa.

18: La Reserva Federal de Estados Unidos, el Banco Central Europeo, el Banco de Japón, el Banco de Canadá, el Banco de Inglaterra y el Banco Nacional Suizo informan "medidas coordinadas" y el aporte de un capital por un valor de US\$ 180.000 millones.

El banco británico Lloyds TSB anuncia la compra de su rival Halifax Bank of Scotland (HBOS) por US\$ 21.800 millones para salvarlo de la quiebra.

19: El Departamento del Tesoro y la Reserva Federal de EE.UU. plantean al Congreso un paquete de medidas legislativas para paliar "los riesgos sistémicos" en los mercados de capitales.

22: Dos instituciones financieras japonesas anunciaron planes de adquirir grandes partes de Morgan Stanley y Lehman Brothers.

Goldman Sachs y Morgan Stanley, se convierten en holding bancario.

23: Berkshire Hathaway, empresa de Warren Buffett, anunció la compra del $9 \%$ de las acciones del banco de inversiones Goldman Sachs.

25: Los activos del mayor banco de ahorro y préstamo de EE.UU., el Washington Mutual, fueron subastados después de que la institución fuera intervenida.

29: El gobierno británico nacionaliza el banco Bradford \& Bingley (B\&B).

Wachovia pasa a manos de Citigroup, su principal rival. 


\section{OCTUBRE 2008}

1: El Senado de EE.UU. aprueba el paquete de rescate de US\$700.000 millones.

3: George W. Bush, promulga la ley del paquete de US\$ 700.000 millones.

5: El alemán Hypo Real Estate (HRE), está cerca del colapso tras fracasar negociaciones para rescatarlo.

8: El gobierno británico anuncia un plan de rescate financiero de casi US\$90.000 millones.

10: Un jueves negro precede a este viernes de caída libre en las bolsas en Asia y Europa. Es la peor semana de la crisis financiera global.

La cotización del barril del petróleo cae a sus niveles más bajos en un año: US\$ 86,59.

13: 15 paises de la zona euro acordaron un plan de acción contra la crisis financiera, que prevé recapitalizar instituciones en riesgo y garantizar préstamos interbancarios.

El gobierno británico controlará un $60 \%$ del Royal Bank of Scotland y un $40 \%$ de la fusión entre Lloyds TSB y HBOS.

14: Déficit presupuestario en Estados Unidos alcanza cifra récord: US\$ 450.000 millones $(3,2 \%$ de $\mathrm{PBI})$.

18: George W. Bush, plantea cumbre internacional sobre la crisis financiera mundial.

19: El presidente de Caisse d'Epargne de Francia, renuncia por la pérdida de unos US\$ 800 millones.

El gobierno de Holanda inyectará US\$ 13.000 millones en ING.

20: La producción industrial de China cae por tercer trimestre consecutivo.

23: Greenspan reconoce error en no haberse regulado los "Credit Default Swaps".

24: Paulson, secretario de Tesoro de EE.UU., indica que han tomado participaciones en bancos regionales y planean hacerlo en compañias de seguros.

30: La Reserva Federal estadounidense redujo la tasa clave de interés de 1,5\% a 1\%

\section{NOVIEMBRE 2008}

4: El precio del petróleo Brent (el crudo de referencia en Europa) cayó por debajo de US\$ 60 el barril por primera vez en 20 meses.

7: El Departamento de Trabajo informó de un marcado aumento en el índice de desempleo, que alcanzó el 6,5\% en octubre, la tasa más alta en los últimos 14 años.

\section{DICIEMBRE 2008}

1: El Buró Nacional de Investigaciones Económicas de Estados Unidos anunció oficialmente que la economía estaba en recesión. El panel señala que la economía comenzó a contraerse en 2007.

4: El presidente de Francia, Nicolás Sarkozy, anunció un paquete de ayuda de 26 mil millones de euros para estimular la economía, que incluirá asistencia a empresas automotrices e inversión pública.

11: El Banco de América anunció que recortará 35 mil empleos en un período de tres años.

Los Bancos Centrales Europeo, británico, sueco y danés reducen nuevamente sus tasas de interés.

16: La Reserva Federal de Estados Unido redujo la tasa de interés de $1 \%$ a $0,25 \%$, la más baja en la historia.

29: El Departamento del Tesoro de Estados Unidos, anunció un paquete de ayuda por valor de US\$ 6 mil millones para la empresa automotriz General Motors.

\section{ENERO 2009}

8: El Banco de Inglaterra redujo su tasa de interés a 1,5\%, la más baja en sus 315 años de historia.

9: Datos oficiales revelan que la tasa de desempleo de Estados Unidos aumentó a 7,2\% en diciembre, la tasa más alta en 16 años.

13: Las exportaciones chinas registran su peor caída en la última década. 
La canciller alemana Angela Merkel anuncia un paquete económico de US\$ 67 mil millones para estimular la economía.

14: Cifras del Departamento de Comercio de Estados Unidos muestran que las ventas del comercio bajaron más de lo esperado en diciembre.

15: El Banco Central Europeo redujo la tasa de interés en la zona euro en medio por ciento para alcanzar $2 \%$.

16: El gobierno de Estados Unidos llegó a un acuerdo para otorgar US\$20 mil millones más al Banco de América.

23: La economía británica entra oficialmente en recesión.

27: El gobierno británico anunció un paquete de ayuda para la industria automotriz por valor de 2.300 millones de libras esterlinas.

28: El Banco Central de España anunció que el país está en recesión por primera vez desde 1993.

\section{FEBRERO 2009}

1: El Foro Económico Mundial de Davos, Suiza, concluyó con un llamado a reconstruir el sistema económico global. El fundador del foro, Klaus Schwab, anunció "una iniciativa de rediseño global" para reformar la banca, la regulación financiera y el gobierno corporativo.

2: El gobierno de China informó que unos 20 millones de migrantes internos -un número tres veces más grande de lo estimado anteriormente- han perdido sus trabajos durante la actual crisis financiera mundial.

3: El Ministerio del Trabajo español informó que el desempleo en ese país aumentó $6 \%$ en enero, lo que significa que hay casi $\mathbf{2 0 0}$ mil desocupados más que el mes anterior.

11: El líder demócrata del Senado de Estados Unidos, Harry Reid, anunció que las dos cámaras del Congreso llegaron a un acuerdo sobre el plan del presidente Barack Obama para estimular la economía del país. El paquete de compromiso será de US\$ 789.000 millones, menor a la cantidad propuesta por Obama de US\$ 900.000 millones.

12: El Banco Mundial dice que aproximadamente 100 millones de personas en países en vías de desarrollo seguirán en la pobreza debido al bajón económico que afecta al mundo. 